Bragt, S. van, Bemt, L. van den, Kievits, R., Merkus, P., Weel, C. van, Schermer, T. PELICAN: a cluster-randomized controlled trial in Dutch general practices to assess a selfmanagement support intervention based on individual goals for children with asthma. Journal of Asthma: 2015, 52(2)

\begin{tabular}{|l|l|}
$\begin{array}{l}\text { Postprint } \\
\text { Version }\end{array}$ & 1.0 \\
\hline $\begin{array}{l}\text { Journal website } \\
\text { Pubmed link }\end{array}$ & $\frac{\text { htt//www.tandfonline.com/action/showCitFormats?doi=10.3109\%2F02770903.2 }}{\underline{\underline{014.952439 \&}}}$ \\
\hline DOI & $10.3109 / 02770903.2014 .952439$ \\
\hline
\end{tabular}

This is a NIVEL certified Post Print, more info at http://www.nivel.eu

\title{
PELICAN: a cluster-randomized controlled trial in Dutch general practices to assess a self- management support intervention based on individual goals for children with asthma
}

StePhanie VAN BRAgt, MSc1, LisetTe VAN DEN Bemt, PhD1, Regien KiEVITS, MD2, Peter Merkus, MD, PhD3 , Chris VAN WeEl, MD, PhD, Prof1,4 AND TJARd SCHERMER, PHD

1 Department of Primary and Community Care, Radboudumc, Nijmegen, The Netherlands, 2 General Practice Kievits en Bloemen, Health Center Hoge Vliert, Vught, The Netherlands,

3 Department of Paediatric, Division of Respiratory Medicine, Radboudumc, Nijmegen, The

Netherlands, and

4 Australian Primary Health Care Research Institute, Australian National University,

Canberra, Australia

\begin{abstract}
Objective: Insufficient asthma management leads to impaired health-related quality of life (HRQL). The aim of this study is to assess whether individualized self-management (ISM) support will improve HRQL in children with asthma compared to enhanced usual care (EUC) in Dutch general practices. Methods: A cluster-randomized controlled trial with 9-month followup. ISM is a nurse-led intervention that is optimized to the needs of children, leading to a written action plan. Power calculation demanded inclusion of 170 children (aged 6-11 years) diagnosed with asthma and active medication use. Results: Outcomes were HRQL of the child (Paediatric Asthma Quality of Life Questionnaire, PAQLQs) and several secondary outcomes. Data of 29 children (mean age 8.6 years, SD 1.7) were analyzed; ISM (n 1/4 15) or EUC (n 1/4 14). Logistic regression analysis (minimal clinical important difference; MCID 0.5) and descriptive analyses were performed. Despite high PAQLQ-s score at baseline (median ISM 6.35, EUC 6.02), a substantial number of subjects from both groups showed MCID of HRQL (ISM 33\%, EUC 57\%). Treatment differences on HRQL were not significant (OR $0.38,95 \%$ CI $0.08,1.69$ ). Secondary outcomes did not show significant differences either, with exception of PAQLQ-s symptoms domain score in favor of EUC. Conclusion: Due to recruitment problems and
\end{abstract}


Bragt, S. van, Bemt, L. van den, Kievits, R., Merkus, P., Weel, C. van, Schermer, T. PELICAN: a cluster-randomized controlled trial in Dutch general practices to assess a selfmanagement support intervention based on individual goals for children with asthma. Journal of Asthma: 2015, 52(2)

underpowered analyses, no firm conclusions on the effectiveness of ISM support for childhood asthma in primary care could be drawn. Still, this study can be considered a valuable pilot study and in the future, there might be better capacity in general practices to commit to such treatment.

\section{INTRODUCTION}

Asthma is a chronic inflammatory pulmonary disease, characterized by variable and recurring symptoms such as breathlessness and wheezing [1]. Poor disease management leads to increased symptoms, exacerbations and impaired health-related quality of life (HRQL) and is responsible for three-quarters of the total healthcare costs for asthma $[2,3]$. Training patients how to self-manage their illness properly, may lead to better asthma control against lower costs. Selfmanagement refers to an individual's own actions which contribute to maintaining, improving or restoring health and treating or preventing exacerbations [4]. Self-management programs for childhood asthma have been widely studied. A Cochrane review with 32 studies assessed the effectiveness of such programs in childhood asthma [5]. These programs were rather diverse, usually nurse-led in a clinic or school and given individually or in groups. This review shows that self-management was effective in improving lung function measures, functional status, quality of life and reducing school absence, restricted activity, emergency room visits and nights disturbed by asthma. Programs were most effective in children with moderate- severe asthma. More recent papers and reviews show potential in improving objective and subjective asthma outcomes as well, but their results were inconsistent [6-9]. Also internetbased monitoring and self-management programs are emerging for youths and adult asthma patients, but for the time being their effectiveness is inconclusive [10-14]. An important difference between individualized selfmanagement (ISM) support and previously studied selfmanagement programs is that other programs often provided standard training with fixed educational topics and were not investigated in general practice settings. The ISM program we developed consists of a nurse-led intervention in which the precise elements are adjusted to the needs of the individual child. These needs are the starting point for ISM and are measured by a self-administered online HRQL questionnaire (called "Pelican instrument"), in which the child selects concrete asthma-related problems before the scheduled visit to the practice nurse. The ISM program is in line with the current advice of the Lung Alliance Netherlands (LAN) to regularly monitor children with asthma, use individualized action plans, educate patients and facilitate self-management [15]. The aim of this study was to assess the effectiveness individualized selfmanagement (ISM) support on improving HRQL in children with asthma compared to enhanced usual care (EUC) in Dutch general practices. Due to considerable recruitment problems, the findings reported in this manuscript should be considered to result from a pilot study.

\section{METHODS}

\section{Design}

The study design was a cluster-randomized controlled trial (RCT) in Dutch general practices. Practices were randomly allocated to enhanced usual care (EUC) alone or individualized self-management (ISM) care supplementary to EUC. All participants 
Bragt, S. van, Bemt, L. van den, Kievits, R., Merkus, P., Weel, C. van, Schermer, T. PELICAN: a cluster-randomized controlled trial in Dutch general practices to assess a selfmanagement support intervention based on individual goals for children with asthma. Journal of Asthma: 2015, 52(2)

were followed for 9 months, in which four visits to the general practice were scheduled. The study protocol has been approved by the Medical Ethics Committee of the Arnhem-Nijmegen region in the Netherlands. Other specific details with regard to the study methods can be found elsewhere [16].

\section{Pelican instrument}

The Pelican instrument is a self-administered online HRQL instrument developed for primary school aged children with asthma (6-11 years). This instrument can be applied for scientific purposes and for individual patient care. The instrument exists of a general part with 22 questions that can be answered on a 5-point Likert scale and an individual part that allows a child to select concrete asthma-related problems that bother him or her in daily life. Details on the development and validation process of the Pelican instrument can be found elsewhere $[17,18]$.

\section{Self-management support}

Children allocated to ISM received self-management support on top of usual care. Before each scheduled visit, children completed the online Pelican instrument. The child's selection of asthma-related problems was the starting point for a sixstep ISM intervention based on shared decision-making. Together with the patient and parent(s), a practice nurse discussed which selected problem would be subject of treatment (Step 1). When needed, details around a problem were di scussed (Step 2), a treatment goal was formulated (Step 3), a brainstorm session on solutions was held (Step 4) and solutions that all involved agreed on were documented in a written action plan (Step 5). Solutions could focus on education, inhalation technique, medication adjustments, therapy adherence, exercise, environment, social impact, self-efficacy and many other individual aspects. During the next visit, the results of the written action plan were evaluated (Step 6) and if the treatment goal was not achieved, the sixstep intervention was repeated [16]. Nurses were trained before the start of the study. During the study, nurses were monitored with a fixed number of feedback/observation moments. Telephone support for specific questions was provided as well.

\section{Enhanced usual care}

Enhanced usual care consisted of an assessment of symptoms, medication use and exposure to triggers according the guidelines of the Dutch College of General Practitioners every 3 months [19]. Usual care was provided by the general practitioner (GP) or practice nurse. Usual care visits would last $10 \mathrm{~min}$ - the standard length of a consultation in Dutch general practice.

\section{General practices}

From February 2011 to July 2013 general practices with a practice nurse employed, were recruited using different recruitment methods. GP care networks were approached and if the study was in scope with their care priorities, mailings, telephone calls and personal requests were send to individual practices that were affiliated to the network.

\section{Participants}

Parents of children with ICPC code R96 were invited by their GPs through written information and were sent a reminder after 2 weeks. Additional information was given by e-mail or telephone. Age-appropriate information on the project was available on the website of the Pelican Project for children 
Bragt, S. van, Bemt, L. van den, Kievits, R., Merkus, P., Weel, C. van, Schermer, T. PELICAN: a cluster-randomized controlled trial in Dutch general practices to assess a selfmanagement support intervention based on individual goals for children with asthma. Journal of Asthma: 2015, 52(2)

(http://koplopers.org/pelikaan; in Dutch). Both legal caregivers had to sign a writfep informed consent (if applicable). After consent, in- and exclusion criteria were assessed. Children aged 6 until 11 years with physician-diagnosed asthma, who had used asthma medication (i.e. bronchodilators and/or inhaled corticosteroids) for at least 6 weeks during the previous year, were included. Exclusion criteria were comorbid conditions that significantly influence HRQL (such as diabetes or congenital heart defects), not being able to attend a regular school class, and insufficient skill in speaking and/or reading the Dutch language.

\section{Practice allocation}

Participating general practices were allocated to the treatment groups by a computerized minimization procedure. Prognostic factors used to stratify minimization were the number of potential participants for the study in a practice (n518 or $\mathrm{n} 18$ pediatric asthma patients) and presence of structured usual care for patients with asthma (yes or no).

\section{Measurements}

Demographic characteristics were inquired using a questionnaire filled out by the parents. At baseline, lung function measures with reversibility testing were performed according to international guidelines [20]. All primary and secondary outcomes were assessed at baseline and after 9 months. The primary outcome of this study was HRQL of the child (measured by the selfadministered Paediatric Asthmarelated Quality of Life Questionnaire - standardized; PAQLQ-s [21,22]). Secondary outcomes were HRQL domain scores of the PAQLQ-s (activities, symptoms and emotions), HRQL of the child measured by the Pelican instrument [17], asthma control (measured by the partly self-administered Child-Asthma Control Test; CACT [23,24], and proxy-rated Asthma Control Questionnaire 6; ACQ6 [25,26]), psychosocial problems (measured by the proxy-rated Strengths and Difficulties Questionnaire; SDQ [27]), and HRQL of the parents (Paediatric Asthma Caregiver Quality of Life Questionnaire; PACQLQ [28]). Subjective asthma experience was assessed by two questions: "Do you worry about having asthma?" (Q1), "To what extent is your life affected by your asthma?" (Q2). Children scored these questions on two visual analogue scales (VAS) ranging from 0 (" "not at all") to 10 ("a lot"). Finally, asthma control (ACQ6), number of exacerbations and school/work absenteeism due to asthma were recorded monthly by the parents in a study diary. Dutch versions of questionnaires were used and psychometric properties of the instruments used (with exception of study diary) appeared to be good. Questionnaires for parents were completed on paper or digitally (through www.SurveyMonkey.com). Children completed their questionnaires on paper, with exception of the web-based Pelican instrument. Parents were reminded twice when questionnaires were not completed within 2 weeks.

\section{Hypotheses and sample size}

The primary hypothesis was that supplementary ISM would be able to significantly improve HRQL (PAQLQ-s, 0.5 points) in $25 \%$ of children with asthma compared to (enhanced) usual care alone. Secondary hypotheses were that ISM would be able to significantly improve HRQL on the Pelican instrument, asthma control (C-ACT, 2 points; ACQ6, 0.5 points), VAS scores on subjective asthma experience, psychosocial problems (SDQ) and HRQL of the parents (PACQLQ, 0.5). According to a multi-level power calculation based on the percentage of children with relevant 
Bragt, S. van, Bemt, L. van den, Kievits, R., Merkus, P., Weel, C. van, Schermer, T. PELICAN: a cluster-randomized controlled trial in Dutch general practices to assess a selfmanagement support intervention based on individual goals for children with asthma. Journal of Asthma: 2015, 52(2)

improvement (0.5) on the PAQLQ-s, a total of 170 study subjects for the study rasve required [16].

\section{Blinding}

This was a single-blinded study. The analyses presented in this manuscript were based on blinded data. The study code was broken after the analyses were concluded.

\section{Statistical analyses}

First, the quality of the data set was investigated (frequencies, normality distributions, missing values, outliers). Missing values were imputed according recommendations of questionnaire developers. If a pre-defined maximum of missing values was exceeded, domain and total scores were not calculated and excluded from further analyses. Only outliers due to input errors were corrected. Initially, multilevel analysis techniques (as recommended for cluster-RCTs) were planned. When the number of subjects per cluster is limited (one to five participants per cluster), however, the "design effect"' is negligible. The design effect of this study after recruitment was 1.1 (based on ICC $1 / 40.04$ and 3.4 participants per practice) as recruitment of study participants was not as successful as planned. Therefore, regular regression analyses were performed, without taking clustering of participants within practices into account. For the primary outcome, an uncorrected logistic regression analysis was done on the proportion of children with a minimal clinical important difference (MCID; 0.5) in PAQLQ-s score between the baseline and follow-up measurement. For most secondary outcomes (i.e. the Pelican instrument, ACQ6, CACT, SDQ, VAS of Q1 and Q2, PACQLQ, exacerbations, school/work absenteeism), explorative analyses were performed. Uncorrected logistic regression analyses were used on the PAQLQ-s domains (activities, symptoms and emotions; MCID 0.5). Group mean values of study diary outcomes over 9 months were calculated and visualized in a line graph. Participants were included in intention-totreat analyses if the primary outcome was known at baseline as well as at the end of the 9-month follow-up. All data were analyzed using SPSS (version 20; SPSS Inc., Chicago, IL).

\section{RESULTS}

\section{General practices}

General practitioner care networks usually refused participation because of other care priorities than childhood asthma (e.g. COPD, diabetes and cardiovascular risk management). A total of 112 general practices was invited to participate of which 28 practices did not respond and 73 other practices refused participation for reasons such as lack of time, participation in other research projects, too few pediatric asthma patients or no affinity. Of the 11 practices that decided on participation, two practices were withdrawn due to lack of sufficient participants, leaving nine practices participating in the study. Figure 1 and Table 1 in Appendix show details regarding recruitment and practice characteristics.

\section{Study participants}

About 224 Children with asthma from the electronic patient record systems of the participating practices were invited (Figure 1). Parents rejected participation mostly because they were convinced that their child no longer had asthma or asthma complaints. Parents of 38 children with asthma gave informed consent, however, five children were excluded from the study because they did not meet in- or exclusion 
Bragt, S. van, Bemt, L. van den, Kievits, R., Merkus, P., Weel, C. van, Schermer, T. PELICAN: a cluster-randomized controlled trial in Dutch general practices to assess a selfmanagement support intervention based on individual goals for children with asthma. Journal of Asthma: 2015, 52(2)

criteria. A total of 33 children started with the study, 15 in the ISM group and 18,ipve the EUC group. One child was lost to followup during the study and three children had too many missing data of the primary outcome, leaving 29 children for the analysis. Table 1 shows demographic and clinical characteristics of the study population.

\section{Effects on the primary outcome}

The PAQLQ-s score at baseline was 6.35 (IQR 5.61-6.78) for ISM and 6.02 for EUC alone (IQR 5.05-6.34). About 33\% (n 1/4 5) of ISM children and 57\% (n $1 / 4$ 8) of EUC children showed a relevant improvement in HRQL (PAQLQ-s MCID 0.5), logistic regression analyses did not show statistically significant differences between groups (Table 2).

\section{[FIGURE 1]}

\section{Effects on secondary outcomes}

Results on uncorrected logistic regression analyses of PAQLQ-s domains between ISM and EUC can be found in Table 2. Due to small numbers of subjects within groups, data were mainly described and not analyzed. Children and parents already scored favorable on secondary outcomes such as health-related quality of life (Pelican, PACQLQ), asthma control (ACQ6, C-ACT), psychosocial problems (SDQ) and number of exacerbations at baseline. Although both groups show improvement on secondary outcomes, it cannot be concluded that there are clinically important differences between ISM and EUC (see Table 1). Figure 2 shows line graphs for asthma control (ACQ6), number of exacerbations (as reported by parents) and school/work absenteeism in the ISM and EUC groups over a 9-month follow-up period. No trends could be detected.

\section{DISCUSSION}

\section{Main findings}

A cluster-RCT was performed in a Dutch population of 33 children (6-12 years) in nine general practices that was, unfortunately, statistically underpowered. The aim was to assess the effectiveness of a nurse-led ISM support supplementary to usual care to improve HRQL in childhood asthma. At baseline, both treatment groups showed high PAQLQ-s score and favorable results on secondary outcomes as well, leaving little room for improvement. Nonetheless, in both groups, a substantial proportion showed a clinically relevant change on HRQL after 9 months (ISM 33\% and EUC 57\%, respectively). Analyses of 29 participants did not show differences on either the primary or the secondary outcomes with exception of PAQLQ-s symptoms domain score in favor of EUC.

\section{[TABLE 1]}

\section{Strengths and limitations of this study}

The most important limitation of this study was the lack of recruiting enough general practices and pediatric asthma patients and, therefore, interpretation of results should be done carefully. GPs mainly mentioned to have other care priorities and lack of time. RCTs are often considered as timeconsuming studies besides patient care [29]. Parents rejected participation mostly because they believed that the asthma diagnosis 
Bragt, S. van, Bemt, L. van den, Kievits, R., Merkus, P., Weel, C. van, Schermer, T. PELICAN: a cluster-randomized controlled trial in Dutch general practices to assess a selfmanagement support intervention based on individual goals for children with asthma. Journal of Asthma: 2015, 52(2)

was invalid or their child did not have current asthma symptoms (Figure 1). Alsopivel parents of children with mild asthma or good asthma control might consider regular monitoring and supplementary guidance in self-management as too intensive care [30]. Another limitation was that the number of visits according to the study protocol (once every 3 months) was higher than what is usually seen in primary care asthma management. In daily practice these children were only seen when parents initiated a visit because of their child's asthma symptoms [19]. Therefore, "usual care" in this study must be considered as "enhanced usual care" [31]. Because the ISM program required frequent visits for the practice nurse to be able to work actively on an action plan with the patient, this visit frequency was chosen to attain comparability between the two treatment arms (i.e. so the number of visits would not cause the difference between groups). The improvement seen on HRQL in the EUC group might therefore also be a result of introducing frequent monitoring visits, next to the additional attention that is paid to the child because of study participation (called Hawthorne effect). Despite of being underpowered, this study still has a couple of strengths, and can thus be considered as a valuable pilot study for further research. First of all, a new ISM intervention that fits very well in the new scope of recent asthma management was investigated in general practices [15]. Another strength is that ISM was implemented by a practice nurse. In outpatient clinics, it is seen that involvement of nurses is already part of usual pediatric asthma care and it is suggested that the level of asthma control in children managed by nurses is not inferior to traditional management by primary or specialized care physicians (against lower health care costs) [32,33]. Since self-management takes considerable time and effort, it is expected that nurses will gain a more prominent role in asthma care in general practices as well $[30,34]$. Finally, it is important to mention that the primary outcome in the study was measured with another HRQL questionnaire (PAQLQ-s) than the HRQL questionnaire that was used as a part of the intervention (i.e. the Pelican instrument). Therefore, "entanglement" of intervention and outcome was prevented.

\section{[TABLE 2]}

\section{Interpretation of findings in relation to previously published work}

To the best of our knowledge, this was the first time that individualized selfmanagement support was investigated in general practices for primary school-aged asthma patients. Therefore, it was difficult to compare these results with previous studies. Although the insignificant results on the effectiveness of ISM on improving health-related quality of life in this study could be explained by underpowered analyses, previous papers on individualized pediatric asthma care in other health care settings show promising results on improving health-related quality of life and several other outcomes $[8,9]$. Furthermore, there is no plausible explanation why the usual care group shows significant improvement on symptoms (measured by PAQLQ-s) compared to usual care + individualized self-management group. It would be likely that this is an incidental finding. 
Bragt, S. van, Bemt, L. van den, Kievits, R., Merkus, P., Weel, C. van, Schermer, T. PELICAN: a cluster-randomized controlled trial in Dutch general practices to assess a selfmanagement support intervention based on individual goals for children with asthma. Journal of Asthma: 2015, 52(2)

\section{[FIGURE 2]}

\section{Implications for future research, policy and practice}

The current study did not show differences between supplementary ISM and usual care alone for childhood asthma in Dutch general practices. However, the analyses were underpowered and both groups showed high HRQL scores at baseline, leaving little room for improvement. Whether or not ISM should be implemented in primary care, can therefore not be concluded from this study. A similar RCT in children with asthma recruited from hospital in the Netherlands has recently been finished as well. Recruitment in that study was successful and further evidence regarding the effectiveness of the Pelican-based ISM intervention will be provided. The study reported in this article and the hospital study will be followed by an in-depth analysis of the content and process of the ISM intervention. ISM is a complex intervention existing of several phases and aiming at patients with different individual treatment goals [35]. These aspects may influence the effectiveness of the intervention and therefore a detailed evaluation is crucial to understand how and why the intervention works or fails. Finally, further research is necessary to assess (cost-) effectiveness of individualized self-management programs for childhood asthma in Dutch primary care. Suggestions are to compare three treatment arms: "unenhanced"' usual care (seeing patients on indication), with routine care (seeing patients on a regular base with a minimum of once a year) and individualized self-management care (as suggested by new national asthma guidelines).

\section{CONCLUSIONS}

The current, underpowered study (which should be considered a pilot study) does not provide sufficient evidence to conclude that the studied ISM support program is effective in improving HRQL in pediatric asthma patients treated in Dutch primary care. Further research into the effectiveness of individualized self-management in primary care is needed but will not be easy considering the recruitment problems in this study. It is questionable whether current preconditions are favorable for an individualized self-management support program such as evaluated in this study. In the future, there might be better capacity in general practices to commit to such a program.

\section{Acknowledgements}

The authors would like to thank all participating children and their parents/caretakers. We are also grateful to all GPs and practices nurses who helped recruiting participants and performed the self-management intervention. Statistician Reinier Akkermans was consulted for statistics. A special thanks goes to Evelien Scheltinga and Riet Cretier who managed the logistics and data collection for this study.

\section{Declaration of interest}

This study was financially supported by the Dutch Lung Foundation (previously Dutch Asthma Foundation), NutsOhra foundation and a grant from the Nijmegen Centre of Evidence-Based Practice (RadboudUMC grant). The authors report no conflicts of interest. The authors alone are responsible for the content and writing of the article.

\section{REFERENCES}


Bragt, S. van, Bemt, L. van den, Kievits, R., Merkus, P., Weel, C. van, Schermer, T. PELICAN: a cluster-randomized controlled trial in Dutch general practices to assess a selfmanagement support intervention based on individual goals for children with asthma. Journal of Asthma: 2015, 52(2)

1. Global Strategy for Asthma Management and Prevention: Global Initiative for Asthma (GINA) [Internet]; 2014. Available at: http:// www.ginasthma.org/ [last accessed 13 Jun 2014].

2. Masoli M, Fabian D, Holt S, Beasley R. The global burden of asthma: executive summary of the GINA Dissemination Committee report. Allergy 2004;59:469-478.

3. Barnes PJ, Jonsson B, Klim JB. The costs of asthma. Eur Respir J 1996;9:636-642.

4. Segall A, Goldstein J. Exploring the correlates of self-provided health care behaviour. Soc Sci Med 1989;29:153-161.

5. Wolf FM, Guevara JP, Grum CM, et al. Educational interventions for asthma in children. Cochrane Database Syst Rev 2003;1: CD000326.

6. Coffman JM, Cabana MD, Yelin EH. Do school-based asthma education programs improve self-management and health outcomes? Pediatrics 2009;124:729-742.

7. Ahmad E, Grimes DE. The effects of self-management education for school-age children on asthma morbidity: a systematic review. J Sch Nurs 2011;27:282-292.

8. Horner SD, Brown A. Evaluating the effect of an asthma selfmanagement intervention for rural families. J Asthma 2014;51: 168-177.

9. Dwamena F, Holmes-Rovner M, Gaulden CM, et al. Interventions for providers to promote a patient-centred approach in clinical consultations. Cochrane Database Syst Rev 2012;12:CD003267.

10. van der Meer V, Bakker MJ, van den Hout WB, et al. Internet-based self-management plus education compared with usual care in asthma: a randomized trial. Ann Intern Med 2009;151:110-120.

11. Rikkers-Mutsaerts ER, Winters AE, Bakker MJ, et al. Internetbased self-management compared with usual care in adolescents with asthma: a randomized controlled trial. Pediatr Pulmonol 2012; 47:1170-1179.

12. Johansen MA, Berntsen GK, Schuster $T$, et al. Electronic symptom reporting between patient and provider for improved health care service quality: a systematic review of randomized controlled trials. part 2: methodological quality and effects. J Med Internet Res 2012; $14: \mathrm{e} 126$.

13. Gustafson D, Wise M, Bhattacharya A, et al. The effects of combining Web-based eHealth with telephone nurse case management for pediatric asthma control: a randomized controlled trial. J Med Internet Res 2012;14:e101.

14. Morrison D, Wyke S, Agur K, et al. Digital asthma selfmanagement interventions: a systematic review. J Med Internet Res 2014;16:e51.

15. Health care guideline for Asthma Children and Youth: Lung Alliance Netherlands [Internet]; 2012. Available at: www.longalliantie.nl/files/9513/7335/4440/Zorgstandaard_Astma_Kinderen_ en_Jongeren.pdf [last accessed 13 Jun 2014].

16. van Bragt $S$, van den Bemt $L$, Thoonen $B$, et al. PELICAN: a quality of life instrument for childhood asthma: study protocol of two randomized controlled trials in primary and specialized care in the Netherlands. BMC Pediatr 2012;12:137.

17. van Bragt S, van den Bemt $L$, Thoonen $B$, et al. Validity, reliability and discriminative capacity of an electronic quality of life instrument (Pelican) for childhood asthma in the Netherlands. Qual Life Res 2014;23:927-938.

18. van den Bemt L, Kooijman S, Linssen V, et al. How does asthma influence the daily life of children? Results of focus group interviews. Health Qual Life Outcomes 2010;8:5.

19. Bindels P, Wouden JVd, Brand P, et al. Dutch College of General Practitioners guideline for pediatric asthma care. Huisarts Wet 2006;49:557-572.

20. Miller M, Hankinson J, Brusasco V, et al. Standardisation of spirometry. Eur Respir J 2005;26:319-338.

21. Raat $\mathrm{H}$, Bueving $\mathrm{HJ}$, de Jongste $\mathrm{JC}$, et al. Responsiveness, longitudinal- and crosssectional construct validity of the Pediatric Asthma Quality of Life Questionnaire (PAQLQ) in Dutch children with asthma. Qual Life Res 2005;14:265-272.

22. Juniper EF, Guyatt G, Feeny DH, et al. Measuring quality of life in children with asthma. Qual Life Res 1996;5:35-46.

23. Liu AH, Zeiger R, Sorkness $C$, et al. Development and crosssectional validation of the Childhood Asthma Control Test. J Allergy Clin Immunol 2007;119:817-825. 
Bragt, S. van, Bemt, L. van den, Kievits, R., Merkus, P., Weel, C. van, Schermer, T. PELICAN: a cluster-randomized controlled trial in Dutch general practices to assess a selfmanagement support intervention based on individual goals for children with asthma. Journal of Asthma: 2015, 52(2)

24. Voorend-van Bergen S, Vaessen-Verberne AA, Landstra AM, et al. Monitoring childhopd asthma: web-based diaries and the asthma control test. J Allergy Clin Immunol 2014;133:1599-1605.

25. Juniper EF, O’Byrne PM, Guyatt GH, et al. Development and validation of a questionnaire to measure asthma control. Eur Respir J 1999;14:902-907.

26. van Dellen QM, Stronks K, Bindels PJ, et al. Predictors of asthma control in children from different ethnic origins living in Amsterdam. Respir Med 2007;101:779-785.

27. Muris $P$, Meesters C, van den Berg F. The Strengths and Difficulties Questionnaire (SDQ)-further evidence for its reliability and validity in a community sample of Dutch children and adolescents. Eur Child Adolesc Psychiatry 2003;12:1-8.

28. Juniper EF, Guyatt GH, Feeny DH, et al. Measuring quality of life in the parents of children with asthma. Qual Life Res 1996;5: 27-34.

29. van der Wouden JC, Blankenstein AH, Huibers MJ, et al. Survey among 78 studies showed that Lasagna's law holds in Dutch primary care research. J Clin Epidemiol 2007;60: 819-824.

30. Thoonen BP, Jones KP, van Rooij HA, et al. Self-treatment of asthma: possibilities and perspectives from the practitioner's point of view. Fam Pract 1999;16:117-122.

31. Freedland KE, Mohr DC, Davidson KW, Schwartz JE. Usual and unusual care: existing practice control groups in randomized controlled trials of behavioral interventions. Psychosom Med 2011;73:323-335.

32. Kuethe $M$, Vaessen-Verberne A, Mulder $P$, et al. Paediatric asthma outpatient care by asthma nurse, paediatrician or general practitioner: randomised controlled trial with twoyear follow-up. Prim Care Respir J 2011;20:84-91.

33. Kuethe MC, Vaessen-Verberne AA, Bindels PJ, van Aalderen WM. Children with asthma on inhaled corticosteroids managed in general practice or by hospital paediatricians: is there a difference? Prim Care Respir J 2010;19:62-67.

34. Thoonen BP, Schermer TR, Akkermans RP, et al. Willingness of patients to perform selfmanagement of asthma and the role of inhaled steroids. Scand J Prim Health Care 2002;20:60-64.

35. Craig P, Dieppe P, Macintyre S, et al. Developing and evaluating complex interventions: the new Medical Research Council guidance. BMJ 2008;337:a1655. 
Bragt, S. van, Bemt, L. van den, Kievits, R., Merkus, P., Weel, C. van, Schermer, T. PELICAN: a cluster-randomized controlled trial in Dutch general practices to assess a selfmanagement support intervention based on individual goals for children with asthma. Journal of Asthma: 2015, 52(2)

TABLES, FIGURES AND APPENDIX

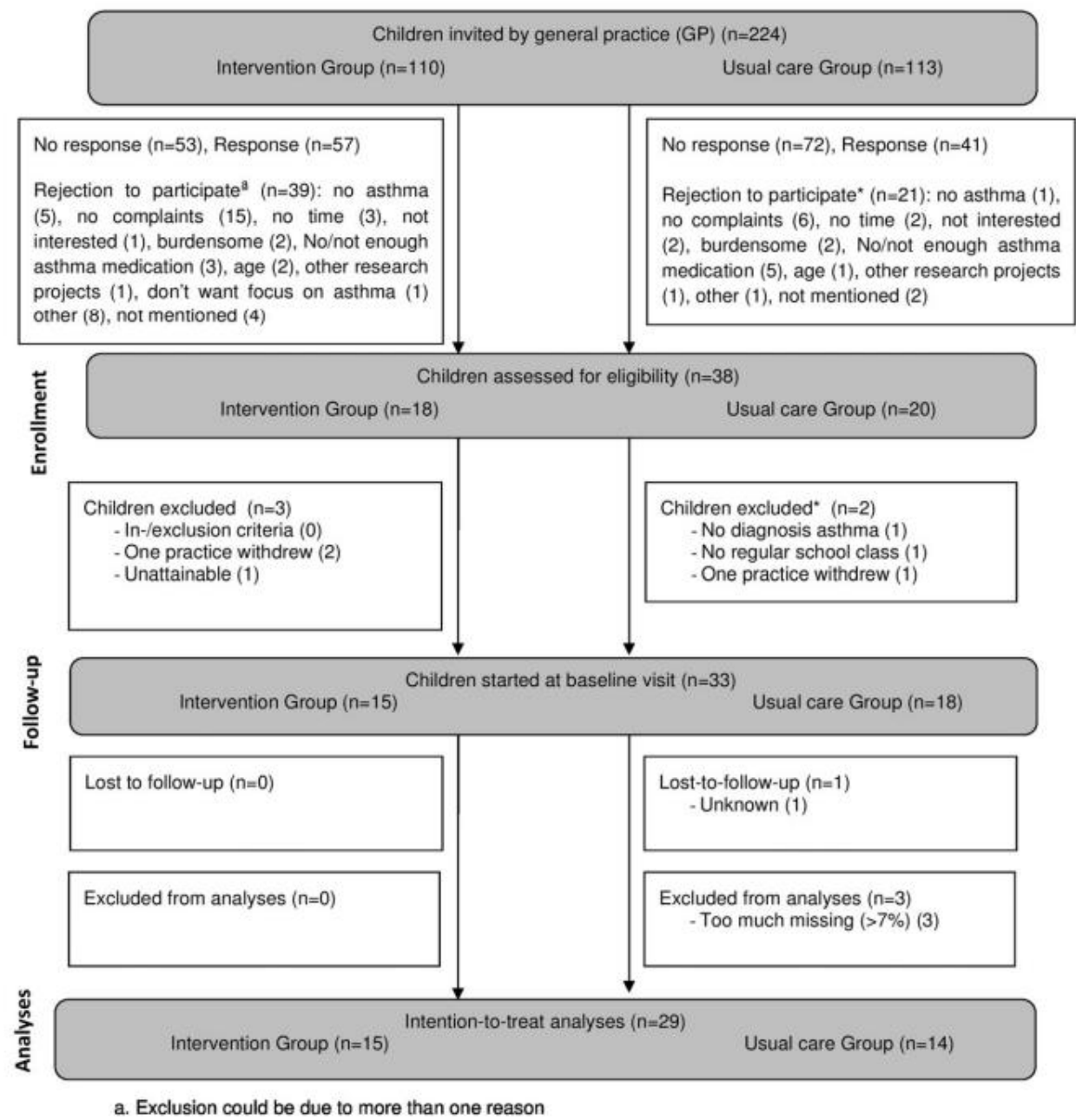

Figure 1. Flowchart of recruitment of childhood asthma patients (6-12 years) treated in Dutch general practices for the Pelican study (a study with the aim to assess effectiveness of nurse-led individualized self-management). 
Bragt, S. van, Bemt, L. van den, Kievits, R., Merkus, P., Weel, C. van, Schermer, T. PELICAN: a cluster-randomized controlled trial in Dutch general practices to assess a selfmanagement support intervention based on individual goals for children with asthma. Journal of Asthma: 2015, 52(2)

Table 1. Demographic and clinical outcomes of pediatric asthma patients participating in the primary care trial of the Pelican study at baseline and after 9-month follow-up [supplementary individualized self-management group (ISM) and enhanced usual care alone (EUC)].

\begin{tabular}{|c|c|c|c|c|}
\hline \multirow[b]{2}{*}{ Outcome (questionnaire) } & \multicolumn{2}{|c|}{$\operatorname{ISM}(n=15)$} & \multicolumn{2}{|c|}{$\operatorname{EUC}(n=14)$} \\
\hline & $\begin{array}{c}\text { Baseline } \\
\text { Median (IQR) }\end{array}$ & $\begin{array}{c}\text { End } \\
\text { Median (IQR) }\end{array}$ & $\begin{array}{c}\text { Baseline } \\
\text { Median (IQR) }\end{array}$ & $\begin{array}{c}\text { End } \\
\text { Median (IQR) }\end{array}$ \\
\hline Gender (male) & $10(66.7)$ & & $8(57.1)$ & \\
\hline Age at baseline (e.g. first visit) (Mean, SD) & $8.4(1.7)$ & & $8.7(1.7)$ & \\
\hline $6-8$ years & $10(66.7)$ & & $9(64.3)$ & \\
\hline $9-11$ years & $5(33.3)$ & & $5(35.7)$ & \\
\hline \multicolumn{5}{|l|}{ Ethnicity } \\
\hline Caucasian & $14(93.3)$ & & $14(100)$ & \\
\hline African & $1(6.7)$ & & $0(0.0)$ & \\
\hline \multicolumn{5}{|l|}{ Socioeconomic status (education) } \\
\hline Low & $0(0.0)$ & & $1(7.1)$ & \\
\hline Middle & $2(13.3)$ & & $4(28.6)$ & \\
\hline High & $13(86.7)$ & & $9(64.3)$ & \\
\hline \multicolumn{5}{|l|}{ Lung function ${ }^{\mathrm{b}}$} \\
\hline FEV1\% pred (Mean, SD) & $111(13.5)$ & & $101(12.7)$ & \\
\hline Reversibility & $2(13.3)$ & & $3(21.4)$ & \\
\hline \multicolumn{5}{|l|}{ Medication use number (\%) } \\
\hline Inhaled corticosteroids & $12(80.0)$ & & $8(57.1)$ & \\
\hline Short-acting beta-adrenoceptor agonist & $9(60.0)$ & & $8(57.1)$ & \\
\hline Long-acting beta-adrenoceptor agonist & $1(6.7)$ & & $2(14.3)$ & \\
\hline Health-related quality of life (PAQLQ-s) & $6.35(1.17)$ & $6.78(0.96)$ & $6.02(0.89)$ & $6.50(0.72)$ \\
\hline Activities & $5.80(1.60)$ & $7.00(1.00)$ & $5.70(2.15)$ & $6.30(1.45)$ \\
\hline Emotions & $6.75(0.75)$ & $7.00(0.25)$ & $6.69(0.75)$ & $7.00(0.38)$ \\
\hline Symptoms & $6.30(1.30)$ & $6.70(1.20)$ & $5.55(1.10)$ & $6.45(0.75)$ \\
\hline Health-related quality of life (Pelican) ${ }^{c}$ & $2.43(0.81)$ & $1.81(1.40)$ & $2.43(1.78)$ & $1.95(1.62)$ \\
\hline Activities & $1.33(1.00)$ & $1.17(0.92)$ & $2.00(2.17)$ & $1.83(1.67)$ \\
\hline Triggers & $2.40(2.00)$ & $1.90(1.85)$ & $2.90(2.40)$ & $2.20(1.85)$ \\
\hline Symptoms & $2.50(1.00)$ & $2.10(1.05)$ & $3.20(1.75)$ & $2.10(2.70)$ \\
\hline Asthma management & $2.40(1.25)$ & $2.00(1.81)$ & $2.75(2.43)$ & $2.13(2.31)$ \\
\hline Social/emotional & $2.00(1.00)$ & $1.00(0.50)$ & $1.50(2.00)$ & $1.25(1.19)$ \\
\hline Health-related quality of life of the parent (PACQLQ) ${ }^{c}$ & $6.85(0.54)$ & $6.96(0.31)$ & $6.62(0.87)$ & $6.85(0.54)$ \\
\hline Activities & $7.00(0.50)$ & $7.00(0.00)$ & $7.00(1.12)$ & $7.00(0.25)$ \\
\hline Emotions & $6.78(0.56)$ & $6.94(0.19)$ & $6.56(1.28)$ & $6.78(0.78)$ \\
\hline Asthma control $(\mathrm{ACQ})^{\mathrm{c}}$ & $0.5(0.6)$ & $0.1(0.5)$ & $0.8(1.4)$ & $0.3(1.0)$ \\
\hline Well controlled <1 $(n, \%)$ & $12(80.0)$ & $12(85.7)$ & $8(57.1)$ & $8(72.7)$ \\
\hline Uncontrolled $\geq 1(n, \%)$ & $3(20.0)$ & $2(14.3)$ & $6(42.9)$ & $3(27.3)$ \\
\hline Asthma control (C-ACT) ${ }^{c}$ & $22.0(6.0)$ & $26.0(4.5)$ & $25.5(3.5)$ & $29.0(2.0)$ \\
\hline Well controlled >22 $(n, \%)$ & $7(50.0)$ & $11(84.6)$ & $5(35.7)$ & $9(81.8)$ \\
\hline Uncontrolled $\leq 22(n, \%)$ & $7(50.0)$ & $2(15.4)$ & $9(64.3)$ & $2(18.2)$ \\
\hline Psychosocial problems (SDQ) ${ }^{\mathrm{C}}$ & $6.0(11.0)$ & $4.5(8.3)$ & $8.0(7.3)$ & $7.0(5.0)$ \\
\hline Normal $(n, \%)$ & $12(80.0)$ & $12(80.0)$ & $11(78.6)$ & $10(71.4)$ \\
\hline Minor $(n, \%)$ & $0(00.0)$ & $2(13.3)$ & $2(14.3)$ & $0(00.0)$ \\
\hline Major $(n, \%)$ & $3(20.0)$ & $0(00.0)$ & $1(7.1)$ & $1(7.1)$ \\
\hline Missing $(n, \%)$ & $0(00.0)$ & $1(6.7)$ & $0(00.0)$ & $3(21.4)$ \\
\hline VAS1: Do you worry about asthma? ${ }^{\mathrm{c}}$ & $1.65(3.80)$ & $0.10(0.25)$ & $2.65(3.86)$ & $0.88(1.37)$ \\
\hline VAS2: Do you feel different because of asthma? & $1.44(3.25)$ & $0.38(3.88)$ & $1.27(4.81)$ & $0.52(0.17)$ \\
\hline
\end{tabular}

${ }^{\mathrm{a} A s t h m a}$ Control Questionnaire (ACQ), Child Asthma Control Test (C-ACT), Enhanced Usual Care (EUC), Percentage predicted of Forced Expiratory Volume in 1 second (FEV1\%pred), Individualised Self-Management (ISM), Interquartile Range (IQR), Paediatric Asthma Quality of Life Questionnaire with standardized activities (PAQLQ-s), Paediatric Asthma Caregiver Quality of Life Questionnaire (PACQLQ), Standard Deviation (SD), Strenghts and Difficulties Questionnaire (SDQ), Visual Analogue Scale (VAS). SDQ Question 13 was missing among 90 of 92 subjects due to organizational problems and was imputed with individual mean of scale.

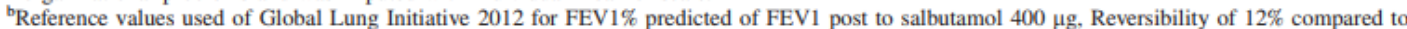
pre-bronchodilator FEV1.

'Number of cases: ACQ end (ISM 14, EUC12), C-ACT baseline (ISM 14, EUC 14), C-ACT end (ISM 13, EUC 11), Pelican end (ISM 14, EUC 12), PACQLQ end (ISM 14, EUC 11), SDQ end (ISM 14, EUC 11), VAS1 \& 2 end (ISM 14, EUC 13).

Table 2. Results of uncorrected logistic regression analyses on quality of life in children with asthma (6-12 years) treated in Dutch general practices according supplementary Individualized Self-Management (ISM) support and Enhanced Usual Care alone (EUC).

\begin{tabular}{lcccc}
\hline & ISM & EUC & & \\
Outcome & $n$ & $n$ & OR $^{\mathrm{a}}$ & $95 \%$ \\
\hline PAQLQ-s & 15 & 14 & 0.38 & $0.08-1.69$ \\
PAQLQ-s activities & 15 & 14 & 0.50 & $0.11-2.19$ \\
PAQLQ-s emotions & 15 & 14 & 0.90 & $0.19-4.17$ \\
PAQLQ-s symptoms & 15 & 14 & $0.20^{\mathrm{b}}$ & $0.04-0.97$ \\
\hline
\end{tabular}

PAQLQ-s, Pediatric Asthma Quality of Life Questionnaire with standardized activities (Minimal Clinical Important Difference $\geq 0.5$ ). a Logistic regression analyses with Odds Ratio (OR, based on MCID; yes or no) and confidence interval presented in the table.

bignificant at $p<0.05$. 
Bragt, S. van, Bemt, L. van den, Kievits, R., Merkus, P., Weel, C. van, Schermer, T. PELICAN: a cluster-randomized controlled trial in Dutch general practices to assess a selfmanagement support intervention based on individual goals for children with asthma. Journal of Asthma: 2015, 52(2)
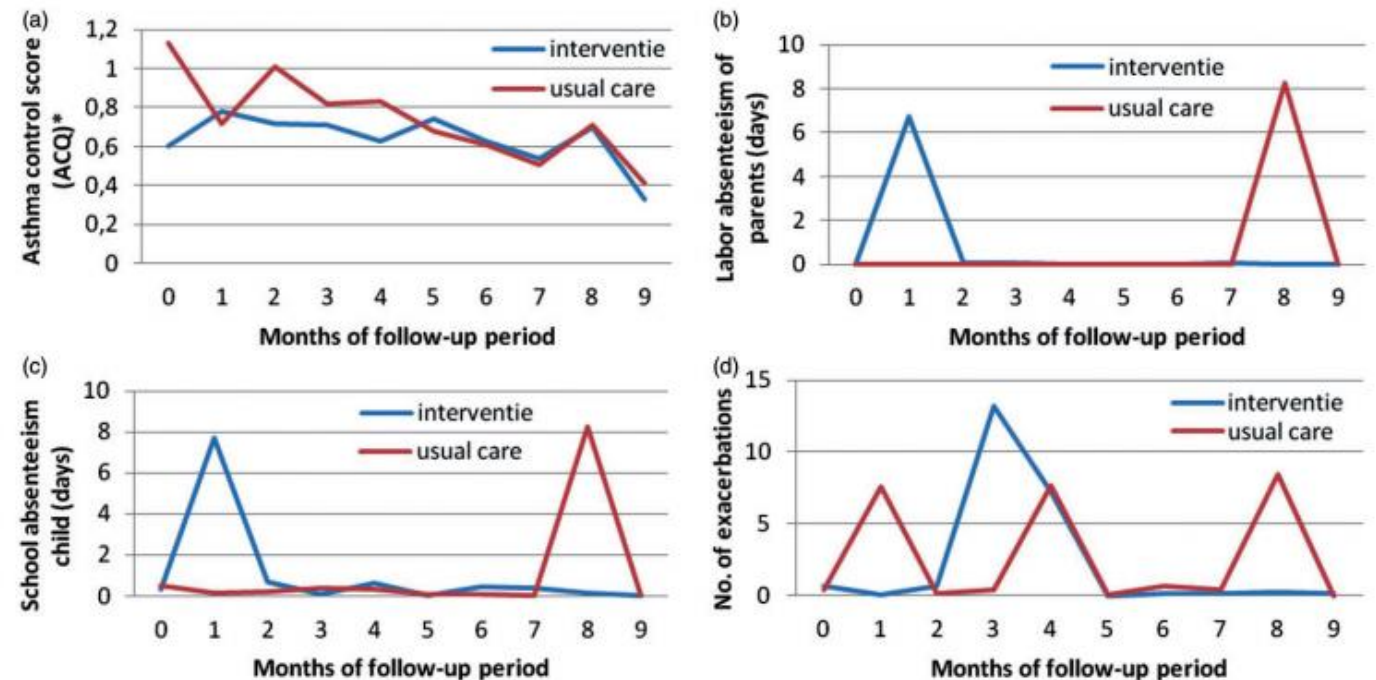

Figure 2. Trends in childhood asthma patients (6-12 years) allocated to the self-management intervention $(n=15)$ and usual care ( $n=14)$ group in Dutch general practices of (a) asthma control (Asthma Control Questionnaire, ACQ; well controlled $<1$ ), (b) number of parent-reported asthma exacerbations, (c) work absenteeism of parents due to child's asthma (in days) and (d) school absenteeism of child due to asthma (in days) over a 9-month follow-up period in the Pelican study. 
Bragt, S. van, Bemt, L. van den, Kievits, R., Merkus, P., Weel, C. van, Schermer, T. PELICAN: a cluster-randomized controlled trial in Dutch general practices to assess a selfmanagement support intervention based on individual goals for children with asthma. Journal of Asthma: 2015, 52(2)

Appendix

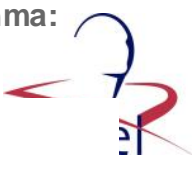

Table 1. Characteristics of general practices that participated in the Pelican project (a study with the aim to assess effectiveness of nurse-led individualized self-management intervention).

\begin{tabular}{|c|c|c|c|}
\hline & $\begin{array}{l}\text { All "center"s } \\
(n=9) n(\%)\end{array}$ & $\begin{array}{l}\text { Intervention group } \\
\quad(n=4) n(\%)\end{array}$ & $\begin{array}{l}\text { Usual care group } \\
\qquad(n=5) n(\%)\end{array}$ \\
\hline Number of participants (that completed trial) & $29(100.0)$ & $15(51.7)$ & 14 (48.3) \\
\hline \multicolumn{4}{|l|}{ Number of general practitioners per practice } \\
\hline$>2$ & $6(66.7)$ & $2(50.0)$ & $4(80.0)$ \\
\hline$<2$ & $3(33.3)$ & $2(50.0)$ & $1(20.0)$ \\
\hline Structured asthma care & $6(66.6)$ & $2(50.0)$ & $4(80.0)$ \\
\hline \multicolumn{4}{|l|}{ Not structured } \\
\hline For children & $1(11.1)$ & $1(25.0)$ & $0(00.0)$ \\
\hline For adults & $2(22.2)$ & $1(25.0)$ & $1(20.0)$ \\
\hline \multicolumn{4}{|l|}{ Frequency asthma care children } \\
\hline On indication (complaints) & $6(66.7)$ & $3(75.0)$ & $3(60.0)$ \\
\hline Once a year & $1(11.1)$ & $1(25.0)$ & $0(00.0)$ \\
\hline Twice a year & $2(22.2)$ & $0(00.0)$ & $2(40.0)$ \\
\hline \multicolumn{4}{|l|}{ Mean duration of consultation } \\
\hline $5-10$ minutes & $1(11.1)$ & $1(25.0)$ & $0(00.0)$ \\
\hline $10-15$ minutes & $7(77.8)$ & $2(50.0)$ & $5(100.0)$ \\
\hline $20-30$ minutes & $1(11.1)$ & $1(25.0)$ & $0(00.0)$ \\
\hline \multicolumn{4}{|l|}{ Practice nurse involved in asthma care } \\
\hline On indication & $6(66.7)$ & $3(75.0)$ & $3(60.0)$ \\
\hline Protocol care (at least once a year) ${ }^{\mathrm{a}}$ & $1(11.1)$ & $1(25.0)$ & $0(00.0)$ \\
\hline Unknown & $2(22.2)$ & $0(00.0)$ & $2(40.0)$ \\
\hline \multicolumn{4}{|c|}{ Delegation of asthma care to practice nurse or assistant $(n=6)$} \\
\hline Complaints history & $4(44.4)$ & $2(50.0)$ & $2(40.0)$ \\
\hline Control of inhalation technique & $6(66.7)$ & $4(100.0)$ & $2(40.0)$ \\
\hline Control of therapy compliance & $5(55.6)$ & $3(75.0)$ & $2(40.0)$ \\
\hline Discussing medication use & $4(44.4)$ & $2(50.0)$ & $2(40.0)$ \\
\hline Discussing medication plan & $0(00.0)$ & $0(00.0)$ & $0(00.0)$ \\
\hline Discussing trigger management & $5(55.6)$ & $3(75.0)$ & $2(40.0)$ \\
\hline \multicolumn{4}{|l|}{ Include experienced quality of life in consultation } \\
\hline Yes, by asking & $9(100.0)$ & $4(100.0)$ & $5(100.0)$ \\
\hline Yes, by a questionnaire & $0(00.0)$ & $0(00.0)$ & $0(00.0)$ \\
\hline \multicolumn{4}{|l|}{ Include experienced asthma control in consultation } \\
\hline Yes, by asking & $8(88.9)$ & $3(75.0)$ & $5(100.0)$ \\
\hline Yes, by a questionnaire ${ }^{a}$ & $1(11.1)$ & $1(25.0)$ & $0(00.0)$ \\
\hline
\end{tabular}

"In one "center", asthma children were structurally seen by the practice nurse, while in other "center's children were treated by the genera practitioner. They measured asthma control by means of the Child-Asthma Control Test (C-ACT). 
Bragt, S. van, Bemt, L. van den, Kievits, R., Merkus, P., Weel, C. van, Schermer, T. PELICAN: a cluster-randomized controlled trial in Dutch general practices to assess a selfmanagement support intervention based on individual goals for children with asthma. Journal of Asthma: 2015, 52(2)

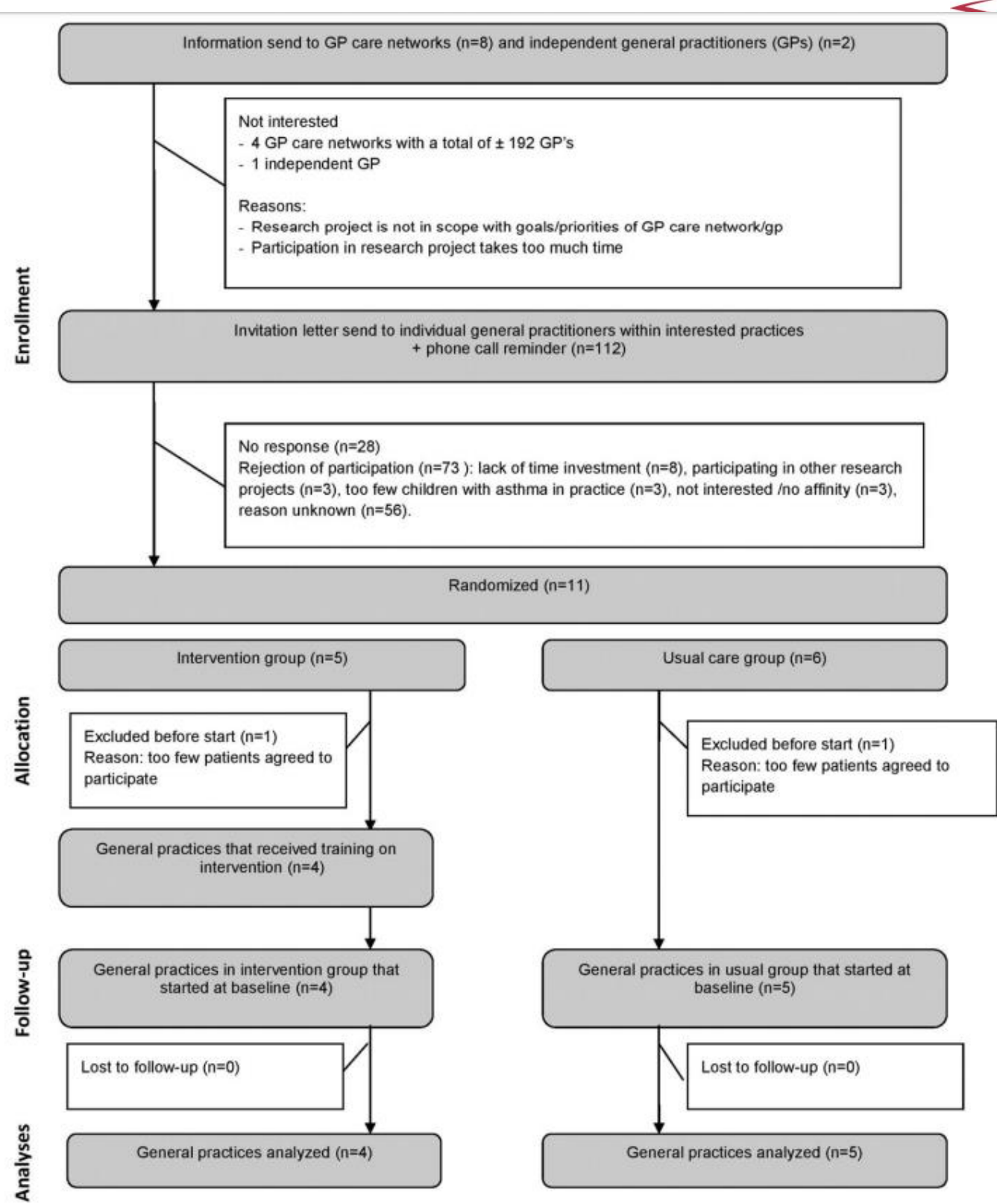

Figure 1. Flowchart of recruitment of general practices in the Netherlands for the Pelican project (a study with the aim to assess effectiveness of nurseled individualized self-management). 